\title{
Flavobacterium aquatile and Flavobacterium meningosepticum: Glucose Nonfermenters with Similar Flagellar Morphologies
}

\author{
JOHN A. WEBSTER AND RUDOLPH HUGH \\ Department of Microbiology, School of Medicine and Health Sciences, George Washington University, \\ Washington, D.C. 20037
}

\begin{abstract}
Flavobacterium aquatile (Frankland and Frankland) Bergey et al. 1923, the type species of the genus Flavobacterium, was originally described as motile and later defined as a nonmotile glucose fermenter. The neotype strain of $F$. aquatile, ATCC 11947, is flagellated, spreads in semisolid agar, and produces oxidative acidity from glucose. Flavobacterium meningosepticum King 1959 was reported to be nonmotile and both oxidative and fermentative. The type strain of $F$. meningosepticum, ATCC 13253, is flagellated, spreads in semisolid agar, and produces oxidative acidity from glucose. The flagellar morphologies of the two strains are similar. The genus Flavobacterium should not include species which ferment glucose.
\end{abstract}

Flavobacterium aquatile (Frankland and Frankland) Bergey et al. 1923, the type species of the genus Flavobacterium, is motile according to Bergey et al. (2). However, the neotype strain of $F$. aquatile (26) is nonmotile and nonflagellated according to Weeks (29), and accordingly the species is described as nonmotile $(30,31)$.

Flavobacterium meningosepticum King 1959 is reported to be nonmotile $(17,28,31)$, but the type strain appears to be motile. Flavobacterium Bergey et al. 1923 is suggested to be fermentative (28), and indeed the genus is included among the fermentative bacteria in Bergey's Manual (31). King (17) reports that F. meningosepticum has "a predominantly oxidative type of utilization of glucose" in oxidative-fermentative $(\mathrm{OF})$ medium.

The neotype strain of $F$. aquatile, $\mathrm{RH} 3019$, and the type strain of $F$. meningosepticum, $\mathrm{RH}$ 540 , were studied with respect to spreading in semisolid agar medium, flagellar morphology, and glucose metabolism in an attempt to resolve these conflicting observations and deductions. Photomicrographs record the flagellar morphologies.

\section{MATERIALS AND METHODS}

Bacterial strains. The strains of $F$. aquatile and F. meningosepticum used in this study and their corresponding strain numbers are shown in Table 1 . Strain RH 3019 was received from the American Type Culture Collection, Rockville, Md. (ATCC) on 29 November 1976. Strain RH 540 was received from E. O. King on 28 March 1958.

Motility medium and flagellum stain. Semisolid Casitone motility medium contains $2 \mathrm{~g}$ of Casitone, 3 $\mathrm{g}$ of agar, 1 liter of distilled water, and thiamine supplement. Casitone broth contains $2 \mathrm{~g}$ of Casitone, 1 liter of distilled water, and thiamine supplement. A 5-ml amount of Seitz-filtered thiamine hydrochloride $(0.01 \mathrm{~g} / \mathrm{ml})$ was added aseptically to 1 liter of sterile, molten, semisolid Casitone motility medium and to sterile Casitone broth. A 1-ml amount of Formalin (38\% formaldehyde) was added to each $4 \mathrm{ml}$ of Casitone broth culture. Formalinized cultures were centrifuged, washed in distilled water, and stained by the method of Leifson (19).

OF media. Bromothymol blue OF (BTB-OF) medium contains $2 \mathrm{~g}$ of Casitone, $0.3 \mathrm{~g}$ of $\mathrm{K}_{2} \mathrm{HPO}_{4}, 0.08 \mathrm{~g}$ of bromothymol blue, $2 \mathrm{~g}$ of agar, and 1 liter of distilled water. The composition of phenol red OF (PR-OF) medium is the same as that of BTB-OF medium, except that $0.03 \mathrm{~g}$ of phenol red replaced the bromothymol blue. These media were modified by the aseptic addition of $5 \mathrm{ml}$ of Seitz-filtered thiamine hydrochloride $(0.01 \mathrm{~g} / \mathrm{ml})$ to 1 liter of molten medium. Seitzfiltered $10 \%$ glucose was added aseptically to sterile BTB-OF, PR-OF, their modifications, and OF basal medium (15) (catalog no. 0688; Difco Laboratories) to a final concentration of $1 \%$. The final $\mathrm{pH}$ of media containing bromothymol blue was 6.8 . The final $\mathrm{pH}$ of media containing phenol red was 7.3. Stiff petrolatum, sterilized at $170^{\circ} \mathrm{C}$ for $2 \mathrm{~h}$, was used to seal media in tubes.

\section{RESULTS}

The bacterial strains used in this study are described in Tables 2 and 3. They were maintained in a freeze-dried state.

F. aquatile $\mathrm{RH} 3019$ and $F$. meningosepticum RH 540 spread from the line of inoculation in semisolid Casitone motility medium. Diffuse spreading growth of strain RH 3019 became apparent after 3 days of incubation at $22^{\circ} \mathrm{C}$. After 3 days of incubation at $35^{\circ} \mathrm{C}$, the spreading growth of strain RH 540 from the line of inoc- 
TABLE 1. Corresponding strain numbers of the neotype strain of $F$. aquatile and the type strain of $F$. meningosepticum

\begin{tabular}{lcc}
\hline \multirow{2}{*}{ Collection $^{a}$} & \multicolumn{2}{c}{ Corresponding strain no. of: } \\
\cline { 2 - 3 } & $\begin{array}{c}\text { F. aquatile } \\
\text { RH } 3019\end{array}$ & $\begin{array}{c}\text { F. meningo- } \\
\text { septicum } \\
\text { RH 540 }\end{array}$ \\
\hline Weeks & F36 $^{b}$ & \\
King & 11947 & 14 \\
ATCC & 8694 & 13253 \\
NCIB & $9758^{c}$ & 10016 \\
NCTC &
\end{tabular}

${ }^{a}$ NCIB, National Collection of Industrial Bacteria, Torry Research Station, Aberdeen, Scotland; NCTC, National Collection of Type Cultures, Central Public Health Laboratory, London, England.

${ }^{b}$ The following designations apparently are used for descendants of the organism isolated by Taylor: F36 (29), Taylor (29), Taylor 36 (31), Taylor F36 (see reference 1).

' See reference 21 .

TABLE 2. Characters of $F$. aquatile RH 3019

\begin{tabular}{|c|c|}
\hline Character & Occurrence \\
\hline Gram-negative rods & + \\
\hline Yellow pigment .... & + \\
\hline Indophenol oxidase $^{a}$ & + \\
\hline Catalase $\ldots \ldots \ldots \ldots \ldots$ & + \\
\hline $\begin{array}{l}\text { Casitone broth with thiamine sup- } \\
\text { plement }\end{array}$ & $+(2)^{b}$ \\
\hline $\begin{array}{l}\text { Growth in brain heart infusion } \\
\text { broth }^{c} \ldots \ldots\end{array}$ & - \\
\hline Oxidative acidity produced in $:^{d}$ & \\
\hline PR-OF glucose $\ldots \ldots \ldots \ldots$ & $+(2)^{e}$ \\
\hline PR-OF lactose $\ldots$. & $+(4)$ \\
\hline PR-OF maltose ... & $+(2)$ \\
\hline PR-OF basal control & - \\
\hline
\end{tabular}

${ }^{a} N, N$-dimethyl-p-phenylenediamine monohydrochloride.

${ }^{b}$ The number in parentheses indicates the number of days of incubation required for the appearance of turbidity.

${ }^{c}$ Difco catalog no. 0037 .

${ }^{d}$ PR-OF, basal medium with thiamine supplement. Carbohydrate concentrations were $1 \%$.

${ }^{e}$ The numbers in parentheses indicate the number of days required for the detection of oxidative acidity.

ulation was less diffuse than that of strain $\mathrm{RH}$ 3019. Strain RH 540 spread more rapidly at $35^{\circ} \mathrm{C}$ than at $22^{\circ} \mathrm{C}$. The rate and degree of spreading of both strains in semisolid Casitone motility medium was different from that of typical, motile Pseudomonas aeruginosa strains which spread rapidly from the line of stab inoculation within a few hours at $22^{\circ} \mathrm{C}$. Although the Gard plate technique $(10,14,16)$ usually permits the selection of motile cells from a predominantly nonmotile population, it did not promote spreading or enhance the recovery of flagellated cells in strains RH 3019 and RH 540.
TABLE 3. Characters of $F$. meningosepticum RH 540

\begin{tabular}{|c|c|}
\hline Character & Occurrence \\
\hline Gram-negative rods & + \\
\hline Yellow pigment .... & + \\
\hline Indophenol oxidase $^{a}$ & + \\
\hline Catalase $\ldots \ldots \ldots$ & + \\
\hline Indole $^{b} \ldots \ldots \ldots$ & + \\
\hline Deoxyribonuclease $\ldots \ldots \ldots$ & + \\
\hline \multicolumn{2}{|l|}{ Oxidative acidity produced in: ${ }^{c}$} \\
\hline OF glucose $\ldots \ldots$ & $+(2)^{d}$ \\
\hline OF lactose $\ldots .$. & $+(2)$ \\
\hline OF maltose $\ldots \ldots \ldots$ & $+(2)$ \\
\hline OF basal medium control ... & - \\
\hline
\end{tabular}

${ }^{a} N, N$-dimethyl-p-phenylenediamine monohydrochloride.

${ }^{b}$ Casitone at $1 \%$ with $0.5 \%$ DL-tryptophan. Indole was detected with Kovacs reagent.

' OF, OF basal medium (Difco). Carbohydrate concentrations were $1 \%$.

${ }^{d}$ The numbers in parentheses indicate the number of days required for the detection of oxidative acidity.

$F$. aquatile RH 3019 was incubated for 4 days at $22^{\circ} \mathrm{C}$ to obtain cells for flagellum staining. The flagellar morphology of strain RH 3019 is shown in Fig. 1 and 2. F. meningosepticum $\mathrm{RH}$ 540 was incubated for 4 days at $35^{\circ} \mathrm{C}$ to obtain cells for flagellum staining. The flagella of strain RH 540 are shown in Fig. 3 through 5 . The flagellar morphologies of the two strains were similar. Most flagellated cells had a short, straight flagellum on a pole or lateral surface (Fig. 1 through 4). A few cells had a longer flagellum at a pole (Fig. 5) or on a lateral surface. The longer flagella sometimes had a greater curvature and occurred less frequently than did the short, straight flagella. Cells with two or more flagella per cell were not encountered in either strain. Flagella were seen on only a few cells of both strains.

$F$. meningosepticum RH 540 grew in OF basal medium (Difco) at $\mathrm{pH}$ 6.8. The glucose medium near the top of the column in the open tube became distinctly yellow after 2 days of incubation at $30^{\circ} \mathrm{C}$, whereas the indicator in the medium under a petrolatum seal showed no significant change in color. After continued incubation, the medium under the seal became slightly yellow, but a distinct yellow color, as seen in the open tube, did not develop. Inoculated basal medium without glucose became deep blue near the top of the column in the open tube, whereas the $\mathrm{pH}$ indicator in the medium under the petrolatum seal did not change color. The results of these experiments on strain RH 540 are shown in color in reference 16. The type strain of Acinetobacter anitratus, ATCC 19606, oxidizes glucose and produces the three control reactions like strain RH 540. 

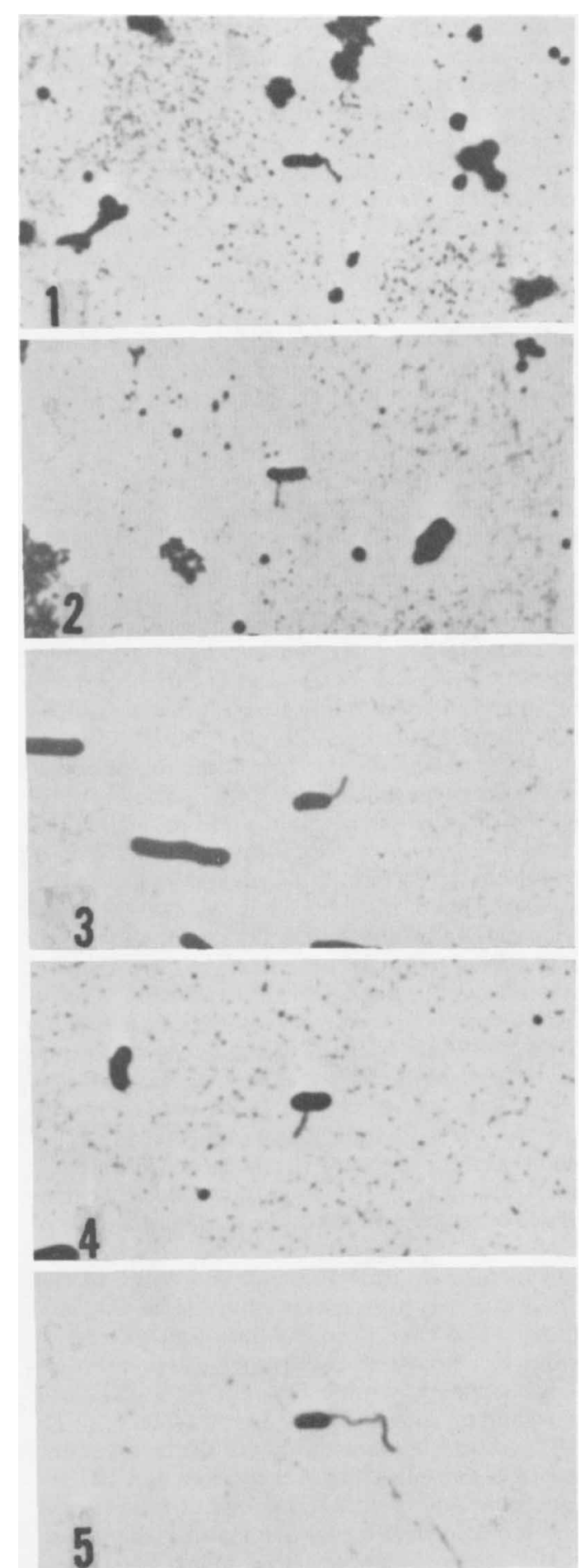

FIG. 1. Photomicrograph of F. aquatile RH 3019 showing a short, straight, polar flagellum. Leifson flagellum stain. $\times 2,500$.
$F$. aquatile $\mathrm{RH} 3019$ did not grow in OF basal medium (Difco), but it grew in PR-OF medium supplemented with thiamine. PR-OF glucose medium near the top of the column in an open tube became distinctly yellow after 2 days of incubation at $30^{\circ} \mathrm{C}$, whereas the indicator in the medium under the petrolatum seal became slightly yellow. Inoculated basal medium without glucose became red near the top of the column in an open tube, whereas the $\mathrm{pH}$ indicator in the medium under the petrolatum seal did not change color. BTB-OF medium supplemented with thiamine did not support the growth of strain RH 3019.

$F$. meningosepticum $\mathrm{RH} 540$ grew well in PR$\mathrm{OF}$ and BTB-OF media. Although thiamine was not necessary for growth, it decreased the incubation time necessary for the indicators in these glucose-containing media to become yellow. After 1 day of incubation at $30^{\circ} \mathrm{C}$, both glucose media supplemented with thiamine became yellow at the surface. PR-OF glucose medium without thiamine required 5 days of incubation, and BTB-OF glucose medium without thiamine required 3 days of incubation to become yellow. There was a slight yellowing in the sealed PROF glucose and BTB-OF glucose media with and without thiamine, but it was more noticeable in media containing phenol red. Inoculated unsealed PR-OF basal medium with and without thiamine became red near the surface, whereas the medium in the sealed tube showed no change in the color of the $\mathrm{pH}$ indicator. Similar changes occurred in BTB-OF basal medium, except that the medium near the top of the column in the open tube became blue.

Strain RH 3019 failed to grow aerobically in brain heart infusion broth (catalog no. 0037; Difco); it grew aerobically in $0.5 \%$ Casitone broth containing glucose and thiamine but failed to grow in this medium in an anaerobic environment (GasPak; BBL Microbiology Systems). Strain RH 540 grew aerobically in brain heart infusion broth but failed to grow in this medium in an anaerobic environment (GasPak).

FIG. 2. Photomicrograph of F. aquatile $R H 3019$ showing a short, straight flagellum apparently on $a$ lateral surface. Leifson flagellum stain. $\times 2,500$.

FIG. 3. Photomicrograph of $F$. meningosepticum RH 540 showing a short, straight, polar flagellum. Leifson flagellum stain. $\times 2,500$.

FIG. 4. Photomicrograph of $F$. meningosepticum RH 540 showing a short, straight flagellum apparently on a lateral surface. Leifson flagellum stain. $\times 2,500$.

Fig. 5. Photomicrograph of $F$. meningosepticum RH 540 showing a long polar flagellum; such flagella are less frequently encountered. Leifson flagellum stain. $\times 2,500$. 


\section{DISCUSSION}

The type species of the genus Flavobacterium, $F$. aquatile, was designated by Bergey et al. (2). This organism has been placed at one time or another in at least five different genera (31). Bacterium aquatilis (sic) Chester 1901, 160 and Pseudomonas aquatilis Migula 1900, 933 are not synonyms of Flavobacterium aquatile (Frankland and Frankland) Bergey et al. 1923. The strain(s) used by Frankland and Frankland (8) as the source of the original description of Bacillus aquatilis appears to be no longer extant. Frankland and Frankland (9) found Bacillus aquatilis "in water obtained from deep wells sunk into the chalk by the Kent Company." E. W. Taylor apparently isolated such a strain from a deep well in Kent, England; this strain was designated by Weeks as F36 and as strain Taylor (29). However, 2 years later this strain was reported to have been isolated from water from deep wells (30), which suggests that several strains of the same species may have been isolated. Strain F36 is reported to have been isolated in 1941 (30), and strain Taylor is reported to have been isolated in 1952 (32). The neotype strain is designated Taylor 36 (31). In 1954, the ATCC assigned accession number 11947 to strain Taylor F36. Weeks (29) concluded that F36 is a strain of $F$. aquatile. Recognizing that there was no type strain for $F$. aquatile, Sneath and Skerman (26) proposed strain F36 as the neotype, and according to Rule $18 \mathrm{e}$ of the International Code of Nomenclature of Bacteria (18), it is the established neotype.

Bacillus aquatilis has an oscillatory motility (8) with vibratory movement (9). Although there may be controversy concerning the degree and kind of motility, there can be no question that Frankland and Frankland described a motile organism $(8,9)$. Their contemporaries, Chester $(6,7)$ and Bergey et al. (2), also described the species as motile. Weeks (31) described $F$. aquatile as nonmotile after reporting in 1955 that strain F36, is nonmotile in a hanging drop preparation (29). Mitchell et al. (23) reported that $F$. aquatile NCIB 8694 swarms after prolonged incubation at $15^{\circ} \mathrm{C}$, and Perry (25) reported that it has gliding motility. The early historical records of the species, two independent observations of swarming and gliding, and spreading growth in semisolid Casitone motility medium permit the conclusion that the species and the neotype strain are motile.

Bacterial motility is often associated with flagella. Strain RH 3019 is flagellated (Fig. 1 and 2) in Casitone broth culture. Although flagellated cells do not necessarily predicate motility, they provide significant evidence that the strain could be motile. Bergey et al. (2) transferred Bacillus aquatilis to the genus Flavobacterium and described the species as peritrichous. The source of this information is not documented. Weeks (29) stained strain F36 by the Leifson procedure, did not observe flagella, and concluded that it was nonflagellated. Motile cells are not necessarily flagellated. Twitching motility is attributed to filamentous surface structures other than flagella (11), but pili (fimbriae) are only visible by electron microscopy (4).

It appears that King (17) intended to designate strain 14 as the type strain for $F$. meningosepticum, and it is recognized as the type (26, 31). Strain RH 540 spreads in semisolid Casitone motility medium and is flagellated (Fig. 3 through 5). Perry (25) did not detect gliding motility in NCTC 10016. Twitching motility and fimbriae were not detected in ATCC 13253 (12). Although King (17) suggested that $F$. meningosepticum is a glucose oxidizer, she does not rule out the possibility of fermentation. Flavobacterium species are described as glucose fermenters $(28,31)$. However, strains RH 3019 and RH 540 produce oxidative acidity from glucose and do not ferment this sugar.

The optimum medium for detection of oxidative acidity produced by $F$. meningosepticum RH 540 is BTB-OF medium or OF basal medium (Difco). In general, bromothymol blue, if it is not toxic, is preferable to phenol red as a pH indicator in OF media. This is because the color transition of bromothymol blue from alkaline to acid is blue to green ( $\mathrm{pH} 6.8$ ) to yellow ( $\mathrm{pH} \mathrm{6.0);}$ in the case of phenol red the transition is from red to orange ( $\mathrm{pH} \mathrm{7.3)} \mathrm{to} \mathrm{yellow} \mathrm{(} \mathrm{pH} 6.8)$. The pH's of OF media are adjusted to the transition color. In these media, the contrast between green and yellow is greater than that between orange and yellow. Bromothymol blue requires a slightly larger drop in $\mathrm{pH}$ to appear yellow than does phenol red. This is an advantage because under a petrolatum seal many glucose oxidizers produce a small quantity of acid, which is not due to fermentation but is attributable to the small quantity of dissolved oxygen in the medium at the time of inoculation and to oxygen which slowly penetrates through the petrolatum seal. Although strains RH 3019 and RH 540 grow and produce a small amount of acid in PROF medium supplemented with thiamine under a petrolatum seal, they fail to grow in a strictly anaerobic environment. The small quantity of acid produced by glucose oxidizers in OF glucose media containing phenol red may cause a noticeable color change toward yellow; however, this slight acid production causes a less noticeable color change when bromothymol blue is used.This is an advantage. Controls help signifi- 
cantly in distinguishing glucose oxidation from glucose fermentation in OF media. Open and sealed tubes of inoculated OF glucose medium are incubated with open and sealed tubes of inoculated basal medium without glucose. Glucose oxidizers produce a distinct yellow color near the top of the column of glucose medium in an open tube. If there is an alkaline reaction in the open tube of the basal medium, then it can be deduced that the accumulated acid in the glucose medium is a result of glucose oxidation.

$F$. aquatile RH 3019 has different growth requirements than strain $R H 540$. Unlike strain RH 540, strain RH 3019 does not grow in brain heart infusion broth or on infusion agar (blood agar base; catalog no. 0045; Difco). Strain RH 3019 requires thiamine, and $\mathrm{NaCl}$ inhibits growth (32). Strain RH 3019 grows in $0.2 \%$ Casitone broth supplemented with thiamine. Yeast extract is not a dependable substitute for thiamine in this medium. Strain RH 3019 grows in this medium at 22 and $30^{\circ} \mathrm{C}$ but not at $35^{\circ} \mathrm{C}$. The optimum medium for detection of oxidative acidity by $F$. aquatile RH 3019 is PR-OF medium containing thiamine. Bromothymol blue inhibits the growth of strain RH 3019.

Although strains RH 3019 and RH 540 fail to ferment glucose and both oxidize glucose, there are significant physiological differences. $F$. aquatile ATCC 11947 produces respiratory ubiquinones (5), and the guanine plus cytosine content of the deoxyribonucleic acid is $32 \mathrm{~mol} \%$ (31). $F$. meningosepticum NCTC 10016 produces menaquinones with the reduced nicotinamide adenine dinucleotide fumarate reductase system (5), and the guanine plus cytosine content of the deoxyribonucleic acid is variously reported as being from 35.5 to $38.4 \mathrm{~mol} \%(5,23,24,27)$. The Flavobacterium species of greatest concern to clinical laboratories is $F$. meningosepticum. $F$. odoratum occurs in urine, wounds, ulcers, and sputum, but there is no hard evidence that it is a human pathogen (14).

Strains RH 3019 and RH 540 spread in motility medium, which is indirect evidence of motility. Both strains possess flagella, and the flagellar morphology of strain RH 3019 is similar to that of strain RH 540. Although both strains may be peritrichous, the wavelength and number of flagella per cell are unlike the wavelength and number usually seen on peritrichous Alcaligenes faecalis, Bordetella bronchicanis, and species of Enterobacteriaceae. Of the $12 \mathrm{Fla}$ vobacterium species, 4 are motile and 3 are peritrichous (31). Perhaps the flagellar morphology of strains RH 3019 and RH 540 is subpolar (20). Boltjes (3) concludes that "it is often difficult to decide whether flagella are peritrichous or polar."
Since the neotype strain of the type species of Flavobacterium is a gram-negative rod which does not ferment glucose, it appears reasonable to conclude that the genus Flavobacterium should not include species which ferment glucose. It should be limited to gram-negative rods which are oxidizers and nonoxidizers of glucose and should not be classified among glucose-fermenting species in Bergey's Manual (31).

\section{REPRINT REQUESTS}

Address reprint requests to: Dr. Rudolph Hugh, Department of Microbiology, School of Medicine and Health Sciences, George Washington University, 2300 Eye Street, N.W., Washington, DC 20037.

\section{LTTERATURE CITED}

1. American Type Culture Collection. 1976. Catalogue of strains. American Type Culture Collection, Rockville, Md.

2. Bergey, D. H., F. C. Harrison, R. S. Breed, B. W. Hammer, and F. M. Huntoon. 1923. Bergeys manual of determinative bacteriology. The Williams \& Wilkins Co., Baltimore.

3. Boltjes, T. Y. K. 1948. Function and arrangement of bacterial flagella. J. Pathol. Bacteriol. 60:275-287.

4. Brinton, C. C. 1959. Non-flagellar appendages of bacteria. Nature (London) 183:782-786.

5. Callies, E., and W. Mannheim. 1978. Classification of the Flavobacterium-Cytophaga complex on the basis of respiratory quinones and fumarate respiration. Int. J. Syst. Bacteriol, 28: 14-19.

6. Chester, F. D. 1897. Report of mycologist: bacteriological work. Annu. Rep. Delaware Agric. Exp. Sta. 9:38-145.

7. Chester, F. D. 1901. A manual of determinative bacteriology. The Macmillan Co., London.

8. Frankland, G. C., and P. F. Frankland. 1889. Ueber einige typische Mikroorganismen im Wasser und im Boden. Z. Hyg. Infektionskr. 6:373-400.

9. Frankland, G. C., and P. F. Frankland. 1894. Microorganisms in water. Longmans, Green, and Co., London.

10. Gard, S. 1938. Das Schwärmphänomen in der SalmonellaGruppe und seine praktische Ausnützung. Z. Hyg. Infektionskr. 120:615-619.

11. Henrichsen, J., and J. Blom. 1975. Correlation between twitching motility and possession of polar fimbriae in Acinetobacter calcoaceticus. Acta Pathol. Microbiol. Scand. Sect. B 83:103-115.

12. Henrichsen, J., and J. Blom. 1975. Examination of fimbriation of some gram-negative rods with and without twitching and gliding motility. Acta Pathol. Microbiol. Scand. Sect. B 83: 161-170.

13. Homes, B., J. J. S. Snell, and S. P. Lapage. 1977. Revised description, from clinical isolates, of Flavobacterium odoratum Stutzer and Kwaschnina 1929, and designation of the neotype strain. Int. J. Syst. Bacteriol. 27:330-336.

14. Hugh, R., and G. L. Gilardi. 1974. Pseudomonas, p. 250-269. In E. H. Lennette, E. H. Spaulding, and J. P. Truant (ed.), Manual of clinical microbiology, 2nd ed. American Society for Microbiology, Washington, D.C.

15. Hugh, R., and E. Leifson. 1953. The taxonomic significance of fermentative versus oxidative metabolism of carbohydrates by various gram-negative bacteria. J. Bacteriol. 66:24-26.

16. Hugh, R., and J. A. Webster. 1978. Photographic survey of glucose-nonfermenting gram-negative rods. American Society for Microbiology, Washington, D.C.

17. King, E. O. 1959. Studies on a group of previously un- 
classified bacteria associated with meningitis in infants. Am. J. Clin. Pathol. 31:241-247.

18. Lapage, S. P., P. H. A. Sneath, E. F. Lessel, V. B. D. Skerman, H. P. R. Seeliger, and W. A. Clark. 1975. International code of nomenclature of bacteria. American Society for Microbiology, Washington, D.C.

19. Leifson, E. 1951. Staining shape, and arrangement of bacterial flagella. J. Bacteriol. 62:377-389.

20. Leifson, E., B. J. Cosenza, R. Murchelano, and R. C. Cleverdon. 1964. Motile marine bacteria. I. Techniques, ecology, and general characteristics. J. Bacteriol. 87:652-666.

21. Medical Reseach Council. 1958. The National Collection of Type Cultures catalogue of species. Medical Research Council Memorandum no. 35. Her Majesty's Stationery Office, London.

22. Migula, W. 1900. System der Bakterien, zweiter band. Gustav Fischer, Jena.

23. Mitchell, T. G., M. S. Hendrie, and J. M. Shewan. 1969. The taxonomy, differentiation, and identification of Cytophaga species. J. Appl. Bacteriol. 32:40-50.

24. Owen, R. J., and S. P. Lapage. 1974. A comparison of strains of King's group IIb of Flavobacterium with Flavobacterium meningosepticum. Antonie van Leeuwenhoek J. Microbiol. Serol. 40:255-264.

25. Perry, L. B. 1973. Gliding motility in some non-spreading flexibacteria. J. Appl. Bacteriol. 36:227-232.
26. Sneath, P. H. A., and V. B. D. Skerman. 1966. A list of type and reference strains of bacteria. Int. J. Syst. Bacteriol. 16:1-133.

27. Sottile, M. I., J. N. Baldwin, and R. E. Weaver. 1973. Deoxyribonucleic acid hybridization studies on Flavobacterium meningosepticum. Appl. Microbiol. 26:535539.

28. Tatum, H. W., W. H. Ewing, and R. E. Weaver. 1974. Miscellaneous gram-negative bacteria, p. 270-294 In E. H. Lennette, E. H. Spaulding, and J. P. Truant (ed.), Manual of clinical microbiology, 2nd ed. American Society for Microbiology, Washington, D.C.

29. Weeks, O. B. 1955. Flavobacterium aquatile (Frankland and Frankland) Bergey et al., type species of the genus Flavobacterium. J. Bacteriol. 69:649-658.

30. Weeks, O. B. 1957. Flavobacterium aquatile, p. 311-312. In R. S. Breed, E. G. D. Murray, and N. R. Smith (ed.), Bergey's manual of determinative bacteriology, 7th ed. The Williams \& Wilkins Co., Baltimore.

31. Weeks, O. B. 1974. Genus Flavobacterium Bergey et al. 1923, 97, p. 357-364. In R. E. Buchanan and N. E. Gibbons (ed.), Bergey's manual of determinative bacteriology, 8th ed. The Williams \& Wilkins Co., Baltimore.

32. Weeks, O. B., and S. M. Beck. 1960. Nutrition of Flavobacterium aquatile strain Taylor and a microbiolog ical assay for thiamine. J. Gen. Microbiol. 23:217-222. 